\title{
Retraction Note to: The Uncommanded Autofeather System Research of Turboprop Aircraft
}

\author{
Bai-ping Yang
}

\section{Erratum to:}

Chapter 38 in: J. Wang (ed.), Proceedings of the First Symposium on Aviation Maintenance and ManagementVolume II, Lecture Notes in Electrical Engineering 297, DOI 10.1007/978-3-642-54233-6_38

This article, published in Lecture Notes in Electrical Engineering Volume 297, 2014, pp 339-347, has been retracted at the request of the author and conference organizer, because of error in data processing.

The online version of the original chapter can be found under DOI 10.1007/978-3-642-54233-6_38

B. Yang $(\bowtie)$

AVIC Xi'an Aircraft Industry Company LTD, Xi'an 710089, China e-mail: qinglongdragon@163.com 